\title{
Effect of Interleukin-2 Combined with Interferon Alpha on Immune Function of Patients with Liver Cancer after Operation
}

\author{
JINCAI SHANG, ZHIWU JI, HAO TIAN, XIN LV, RUIGANG CHEN, XINGQUAN WANG AND DEWANG SU* \\ Office of General Practitioner, First Affiliated Hospital of Jiamusi University, Jiamusi 154002, China
}

Shang et al.: IL-2 Effect with IFN-A On Liver Cancer Patients after Operation

\begin{abstract}
This study aims to analyze the effect of interleukin-2 combined with interferon alpha on the immune function of patients with liver cancer after operation. A total of 160 patients with liver cancer were selected as research objects and divided into study group and control group, each containing 80 patients. Patients in the control group were treated with interferon alpha after surgery, while patients in the study group were treated with interleukin-2 combined with interferon alpha after surgery. The safety integrity level-12 was significantly higher in study group than in control group, $p<0.05$. The combination therapy of interleukin-2 and interferon alpha can effectively improve the immune function of patients with liver cancer after operation.
\end{abstract}

Key words: IL-2, IFN- $\alpha$, SIL-12, liver cancer, immune effect

Liver cancer is malignant tumor occurring in liver. There are two kinds of liver cancer: primary liver cancer and metastatic liver cancer. Generally speaking, liver cancer is usually referred to as primary liver cancer. Primary liver cancer (primary carcinoma of liver) is carcinomas occurring in hepatocytes or intrahepatic cholangiocytes. According to the related data, it is found that liver cancer has higher morbidity in China, ranking the forth of common malignant tumor and the third fatal cause of the tumor, so it is a serious disease that endangers people's life ${ }^{[1-3]}$. Hepatocellular carcinoma (Hepatocellular Carcinoma, HCC), intrahepatic bileduct(Intrahepatic Cholangiocarcinoma, ICC) and HCC-ICC are the three different pathological types in primary liver cancer, which have a great difference in pathogenesis, biological behavior, histological patterns, treatment and prognosis. Main postoperative complications of liver cancer can be listed as follow. First, Postoperative bleeding. As the patient's liver function is not good, clotting function will be affected, so postoperative bleeding may easily occur. Second, postoperative liver insufficiency. Since all patients with liver cancer have cirrhosis, after surgical resection, the remaining liver may not meet the needs of the patient and the patient's liver failure is serious enough to lead to death. Third, postoperative infection. If there is effusion exudation in the incision of liver after operation, infection may be resulted. In addition, the occurrence of biliary fistula 3-5 d after surgery may also cause infection. Therefore, it is very important to adopt scientific treatment after liver cancer surgery to improve the immune function of patients. In recent years, the morbidity of liver cancer (as shown in fig. 1) has increased worldwide, ranking the fifth among malignant tumors. The etiology of primary liver cancer is not completely clear. It is commonly believed that it is resulted from synergistic effect of multiple factors. According to epidemiological investigation, it is believed that it is closely related to viral hepatitis, cirrhosis, aflatoxin contamination, family history and
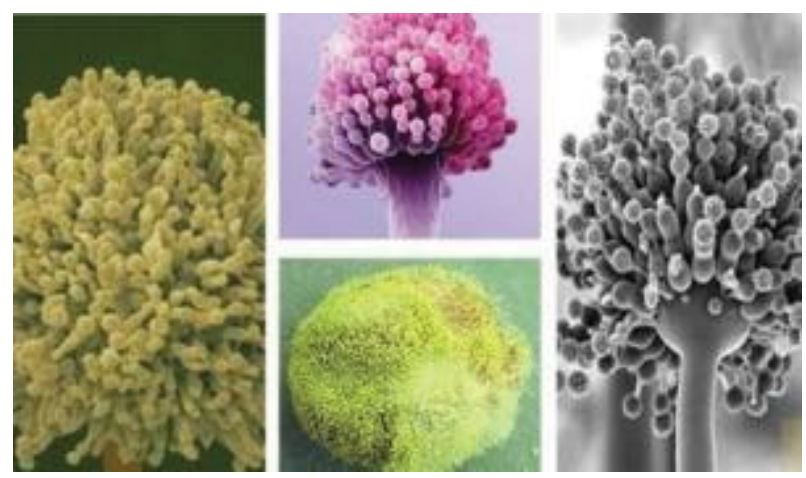

Fig. 1: Aflatoxin

*Address for correspondence

E-mail: sudewang2004@126.com

Special Issue 8, 2020

Indian Journal of Pharmaceutical Sciences 
genetic factors and $s o \mathrm{on}^{[4-5]}$. Surgical treatment is the main treatment for liver cancer patients. In this study, effect of interleukin-2 combined with interferon alpha (IFN- $\alpha$ ) on the immune function of patients with liver cancer after operation was observed and analyzed. 160 patients who had been diagnosed as liver cancer in our hospital during the period from January 2015 to December 2018 (as shown in fig. 2) were selected as subjects. The inclusion criteria: In the four tests of ultrasound and alpha fetoprotein (AFP), dynamic enhanced Magnetic resonance imaging (MRI), dynamic enhanced Computed tomography (CT), contrast enhanced ultrasound, contrast enhanced ultrasound and pulmonary dynamic enhanced MRI, patients were included in the study if more than two showed significant enhancement of arterial lesions and decreased enhancement of portal vein or delayed stage ${ }^{[6]}$. The patients had the right to know and signed a formal informed consent. Those with other complications, mental disorder or lower ability of communication were excluded. The patients were randomly divided into research group and control group with 80 cases in each group. Among them, there were 45 males and 35 females in research group with age ranging from 38 to $70 \mathrm{y}$ old and the average age being $(55.7+3.2) \mathrm{y}$ old, all of which were single mass and diameter was 3-10 $\mathrm{cm}$ with the average diameter being $(7.3+0.5) \mathrm{cm}$; There were 48 males and 32 females in control group with age ranging from 40 to $68 \mathrm{y}$ old and average age being $(56.8+3.6)$ y old, all of which were single mass and diameter was $3-10 \mathrm{~cm}$ with average diameter being $(7.6+1.2) \mathrm{cm}$. Comparing the data of two groups, the results showed that there was comparability $(p>0.05)$. Patients in the study group and the control group were given different postoperative treatment regimens. In fact, patients in the control group were given simple IFN- $\alpha$ therapy, while patients in the study group were given a combination therapy of interleukin-2 and IFN- $\alpha$. The treatment method of the study group can be described as follows: $2 \mathrm{w}$ after the operation, patients were given intravenous infusion of interleukin-2 (1 million $U$ ) and intramuscular injection of IFN- $\alpha$ (1 million $\mathrm{U})$. In contrast, the control group was given only intramuscular injection of IFN- $\alpha$ ( 1 million $U$ ). The treatment for both groups was conducted once a day, with 10 consecutive $d$ as a complete course, with a total of 3 consecutive courses. The content of IL-12 for peripheral blood in research group and control group was examined by means of double-antibody sandwich enzyme-linked immunosorbent assay (ELISA), while the levels of $\mathrm{CD}^{+}, \mathrm{CD}^{+}, \mathrm{CD}^{+}$and $\mathrm{CD} 56^{+}$were observed and recorded and the patients' cellular level of CD4/CD8 and natural killer cell (NK) was recorded and compared. The used statistical analysis software was SPSS21.0. The measurement data were expressed in the ways of average number \pm mean number $(\overline{\mathrm{x}} \pm \mathrm{s})$ and $t$ was used for group comparison. The count data were expressed in the way of natural number (n) and percentage (\%) and $\mathrm{X}^{2}$ was used for group comparison. When $\mathrm{p}<0.05$, the difference was of statistical value. As shown in Table 1, before treatment the level of safety integrity level-12 (SIL-12) research group was $(203.6+14.2) \mathrm{pg} / \mathrm{ml}$, while that of control group was $(201.8+13.9) \mathrm{pg} / \mathrm{ml}$, without significant difference between two groups. There was no statistical significance $(p>0.05)$. After the implementation of different schemes, the level of SIL-12 in research group was $(249.3+11.8) \mathrm{pg} / \mathrm{ml}$ and that of control group was $(204.9+10.5) \mathrm{pg} / \mathrm{ml}$. Through comparing with research group, conditions of patients were significantly improved after treatment and there was a significant difference between two groups, with statistical significance $(p<0.05)$. As shown in Table 2, before and after treatment, the level of $\mathrm{CD}^{+}, \mathrm{CD}^{+}, \mathrm{CD}^{+}$and

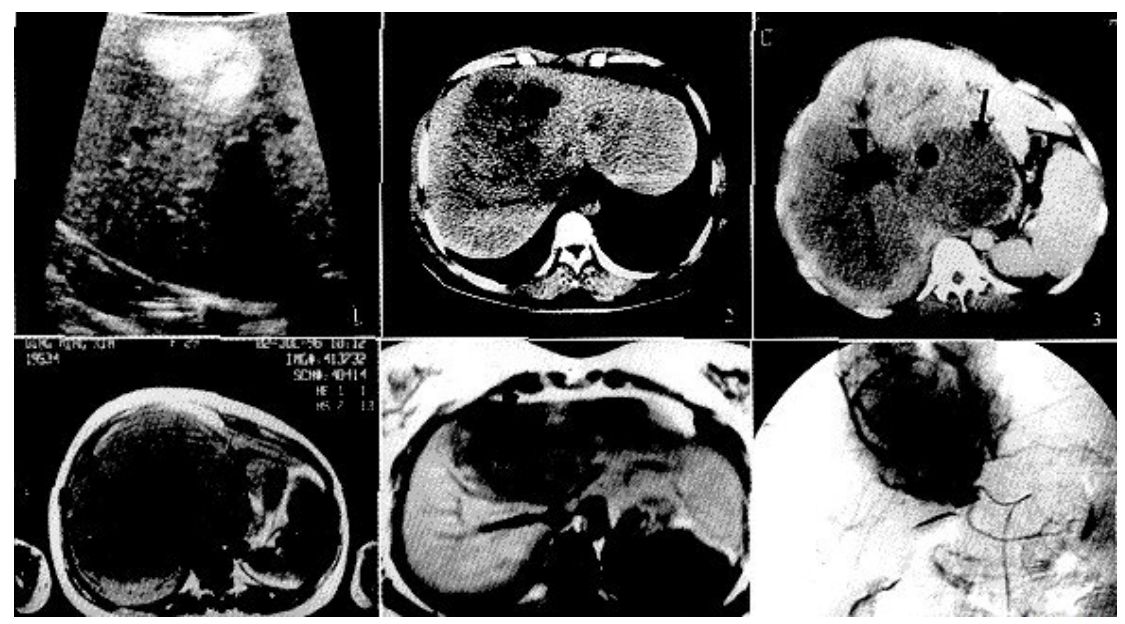

Fig. 2: Imaging fig of One Patient with Liver Cancer 
TABLE 1: COMPARISON FOR LEVELS OF SIL-12 IN TWO GROUPS BEFORE AND AFTER TREATMENT ( $\overline{\mathbf{X}} \pm \mathbf{s})$

\begin{tabular}{|c|c|c|c|}
\hline Groups & Cases & Before treatment $(\mathrm{pg} / \mathrm{ml})$ & After treatment (pg/ml) \\
\hline Research Group & 80 & $203.6 \pm 14.2$ & $249.3 \pm 11.8$ \\
\hline Control Group & 80 & $201.8 \pm 13.9$ & $204.9 \pm 10.5$ \\
\hline $\mathrm{t}$ & & 0.29 & 9.41 \\
\hline $\mathrm{p}$ & & $>0.05$ & $<0.05$ \\
\hline
\end{tabular}

TABLE 2: COMPARISON FOR CHANGES IN LYMPHOCYTE PHENOTYPES BEFORE AND AFTER TREATMENT ( $\overline{\mathbf{x}} \pm \mathbf{s})$

\begin{tabular}{lccc}
\hline Index & Time & Research Group $(\mathrm{n}=80)$ & Control Group $(\mathrm{n}=80)$ \\
\hline $\mathrm{CD3}^{+}(\%)$ & Before Treatment & $20.45 \pm 1.50$ & $20.11 \pm 1.49$ \\
& After Treatment & $29.70 \pm 2.10$ & $20.14 \pm 1.37$ \\
$\mathrm{CD} 4^{+}(\%)$ & Before Treatment & $12.04 \pm 1.11$ & $11.95 \pm 1.07$ \\
& After Treatment & $19.96 \pm 2.11$ & $11.98 \pm 1.03$ \\
$\mathrm{CD} 8^{+}(\%)$ & Before Treatment & $8.55 \pm 1.73$ & $8.63 \pm 1.22$ \\
& After Treatment & $17.80 \pm 1.83$ & $8.53 \pm 1.21$ \\
$\mathrm{CD} 56^{+}(\%)$ & Before Treatment & $12.79 \pm 1.60$ & $12.63 \pm 1.94$ \\
& After Treatment & $18.05 \pm 1.62$ & $12.80 \pm 1.75$ \\
\hline
\end{tabular}

TABLE 3: COMPARISON FOR LEVELS OF CD4/CD8, NK CELL IN TWO GROUPS BEFORE AND AFTER TREATMENT ( $\overline{\mathbf{x}} \pm \mathbf{s})$

\begin{tabular}{lccccc}
\hline Groups & \multirow{2}{*}{ Cases } & \multicolumn{2}{c}{ CD4/CD8 } & \multicolumn{2}{c}{ NKCell (\%) } \\
\cline { 2 - 5 } Research Group & & Before Treatment & After Treatment & Before Treatment & After Treatment \\
Control Group & 80 & $1.18 \pm 0.32$ & $1.80 \pm 0.31$ & $17.30 \pm 4.26$ & $31.09 \pm 6.38$ \\
$\mathrm{t}$ & 80 & $1.07 \pm 0.42$ & $1.15 \pm 0.45$ & $17.80 \pm 4.15$ & $10.69 \pm 3.26$ \\
$\mathrm{p}$ & & 1.56 & 6.35 & 0.28 & 10.25 \\
\hline
\end{tabular}

$\mathrm{CD}^{+} 6^{+}$in control group had not significantly changed, without statistical significance $(\mathrm{p}>0.05)$; The level of $\mathrm{CD}^{+}, \mathrm{CD}^{+}, \mathrm{CD}^{+}$and $\mathrm{CD} 56^{+}$in research group after treatment was significantly higher than that before treatment, with statistically significance in differences $(\mathrm{p}<0.05)$. As shown in Table 3, before the treatment there was no significant difference between research group and control group ( $>0.05)$, without statistical significance. After the implementation of different treatments, the improvement of patients in research group was obviously superior to that of control group $(p<0.05)$, with statistical significance. Cases of primary liver cancer are similar to those of other malignancies, occurring significant decrease in immune function. After a large number of clinical studies and practical experience, it shows that interleukin-12 (IL-12) and interferon alpha (IFN- $\alpha$ ) can enhance cellular immune functions and effectively treat tumors, which was approved in many practical treatments ${ }^{[7-8]}$. However, there are not enough research materials to fully demonstrate its effect on enhancing the immune function. Change in cell phenotype is able to respond to changes in T cell subsets. During the treatment, changes in IL-12 can also be an important indicator to show the immune function ${ }^{[9-10]}$. IL-12, also known as cytotoxic lymphocyte maturation factor and NK stimulator, is cytokines of heterodimer produced by mononuclear macrophages and lymphocyte $\mathrm{B}$ and so forth ${ }^{[11-13]}$. Endogenous IL-12 may partly indirectly mediated IL-2 and anti-interleukin-12 for response could inhibit IFN $-\gamma$ produced by $50 \%$ of PBLs in the body which are induced by IL-2. Thus, the important ways for IL-2 to improve immunityisIL-12 mediation. The results of this study show that IL-12 in serum of the patients with primary liver cancer is relatively lower ${ }^{[14,15]}$. When the patients in research group take the way of combining IL-2 with IFN- $\alpha$, the level of IL-12 is increased significantly. Meanwhile, the levels of $\mathrm{CD}^{+}, \mathrm{CD}^{+}$, $\mathrm{CD}^{+}$and $\mathrm{CD}^{2} 6^{+}$in research group are significantly increased, showing the enhancement of activity in killer $\mathrm{T}$ cells and natural killer cells ${ }^{[16]}$. The activity is enhanced. Therefore, the combination of IL-2 and IFN $-\alpha$ can stimulate the release of IL-12 in the body, form an important factor to induce anti-tumor immunity and obviously enhance the cellular immune function. For future studies, more studies with large sample data are needed to make a full demonstration. To sum up, the combination therapy of IL-12 and IFN- $\alpha$ can increase the secretion of endogenous IL-12, thereby demonstrating the anti-tumor immune effect and 
improving the immune function of the body. Therefore, such method is worth of being popularized into the clinical treatment.

\section{Conflict of interests:}

The authors declared no conflicts of interest.

\section{REFERENCES}

1. Pan G, Jin ZG, Han JX. Comparative Study of IL-2 Combined with INF- $\alpha$ and Single Agent Cisplain in the Treatment of Malgnant Pleural Effusion. Anhui Med Pharm J 2014;18:34951.

2. Zhao JJ, Bi XY, Huang Z, Zhao H, Yan T, Zhou JG, et al. Effect of different nutrition support methods on primary liver cancer patients with hepatectomy: A controlled prospective study. J Med Res 2014;43:75-9.

3. Gurung P, Malireddi RS, Anand PK, Demon D, Walle LV, Liu $\mathrm{Z}$, et al. Toll or interleukin-1 receptor (TIR) domain-containing adaptor inducing interferon- $\beta$ (TRIF)-mediated caspase-11 protease production integrates Toll-like receptor 4 (TLR4) protein-and Nlrp3 inflammasome-mediated host defense against enteropathogens. J Biol Chem 2012;287:34474-83.

4. Refaat A, Zhou Y, Suzuki S, Takasaki I, Koizumi K, Yamaoka $\mathrm{S}$, et al. Distinct roles of transforming growth factor- $\beta$ activated kinase 1 (TAK1)-c-Rel and interferon regulatory factor 4 (IRF4) pathways in human T cell lymphotropic virus 1-transformed T helper 17 cells producing interleukin-9. J Biol Chem 2011;286:21092-9.

5. Konishi H, Shirabe K, Yoshiya S, Ikeda T, Ikegami T, Yoshizumi $\mathrm{T}$, et al. Hepatic interferon-gamma-induced protein-10 expression is more strongly associated with liver fibrosis than interleukin-28 B single nucleotide polymorphisms in hepatocellular carcinoma resected patients with chronic hepatitis C. Hepatol Res 2013;43:1139-47.

6. Xiao DY. Effects of different administration method on influenza-like adverse drug reaction induced by Interlerkin-2 and Interferon- $\alpha$. Evaluation Analysis of Drug-use in Hospital of China 2016;16(04):496-8.

7. Wang H, Pan YG, Xia JT, Zhou MM, Cai C. Clinical effect of transcatheter arterial Chemoembolizaiton in treatment of primary liver cancer: Application and research advances. J Clin Hepatol 2018;34(02):414-8.

8. Liang K, Ma J, Qu Y, Zheng BY, Qiao T. Effect of
Astragaloside on Interleukin-2, Interleukin-4 and Interleukin-6 in Chemotherapy induced anemic mice. Chin Medical Herald 2015;12(18):16-8.

9. Zhao CC, Gao XQ, Xue J, Cong Z, Zhang WL, Chen T, et al. Interleukin-21 up-regulates interleukin-21R expression and interferon gamma production by CD8+ cells in SHIV-infected macaques. Exp Biol Med 2013;238(4):400-9.

10. Wagner B, Wimer C, Freer H, Osterrieder N, Erb HN. Infection of peripheral blood mononuclear cells with neuropathogenic equine herpesvirus type- 1 strain Ab4 reveals intact interferon- $\alpha$ induction and induces suppression of anti-inflammatory interleukin-10 responses in comparison to other viral strains. Vet Immunol Immunopathol 2011;143:116-24.

11. Chen $\mathrm{K}$, Wang XM, Chen F, Bai J. In vitro antimicrobial and free radical scavenging activities of the total flavonoid in petal and stamen of Crocus sativus. Indian J Pharm Sci 2017;79(3):482-7.

12. Bawari S, Sah AN, Tewari D. Urolithiasis: An update on diagnostic modalities and treatment protocols. Indian J Pharm Sci 2017;79(2):164-74.

13. Iyer VV, Tejal A, Poddar A, Maithili D, Rasika LG, Bendre A, et al. An indian perspective of some recent developments in polio, dpt, zika and rotavirus vaccines. Indian J Pharm Sci 2017;79(2):175-85.

14. Margret AA, Begum TN, Kumar AG. Discerning the Potential of Chitosan Extracted from Bio resources as a Competent Brain Drug Carrier to Cross the Blood Brain Barrier. Indian J Pharm Sci 2017;79(2):186-96.

15. Baghel US, Nagar A, Pannu MS, Singh D, Yadav R. HPLC and HPTLC methods for Simultaneous Estimation of Quercetin and Curcumin in Polyherbal Formulation. Indian J Pharm Sci 2017;79(2):197-203.

16. Kathpalia H, Patil A. Formulation and evaluation of orally disintegrating films of levocetirizine dihydrochloride. Indian J Pharm Sci 2017;79(2):204-11.

This is an open access article distributed under the terms of the Creative Commons Attribution-NonCommercial-ShareAlike 3.0 License, which allows others to remix, tweak, and build upon the work non-commercially, as long as the author is credited and the new creations are licensed under the identical terms

This article was originally published in a special issue, "Trends in Therapeutic Management of Various Clinical Conditions II" Indian J Pharm Sci 2021:83(2)Spl issue;119-122 